\title{
騒音の入射方向情報を用いた仮想マイクロホン法による能動音響制御*
}

\author{
木庭洋介 ${ }^{* 1}$, 近藤大介 ${ }^{* 2}$, 雉本信哉 ${ }^{* 3}$
}

\section{Active Noise Control Using a Virtual Sensing Algorithm with Incident Direction Information of Noise}

\author{
Yosuke KOBA*1, Daisuke KONDO and Shinya KIJIMOTO \\ ${ }^{* 1}$ Department of Mechanical Engineering, Kyushu University \\ 744, motooka, nishi-ku, Fukuoka, 819-0395, Japan
}

Local active noise control systems create a zone of quiet around a physical error sensor location. The zone of quiet is generally small, and as such, the physical error sensor is placed at the desired location of sound attenuation, which is usually inconvenient. Virtual sensing algorithms have been developed to aim for creating the zone of quiet at virtual sensor location that is remote from the physical error sensor. However the sound attenuation of the traditional virtual sensing algorithms worsen by change of primary source location that alter the transfer characteristics between a physical sensor and a virtual sensor. This paper presents a method to maintain the sound attenuation at a virtual location in change of sound incident direction of primary source and show positive results of experiments in an anechoic room. The proposed method estimate sound incident direction of primary source to use signals of two microphones and be able to switch between an appropriate filter that is measured in preliminarily identification stage to estimate signal at virtual sensor location.

Key Words : Active Noise Control, Virtual Sensing, RMT Algorithm, Active Shielding

1. は じめに

誤差マイクロホン位置の騒音を低減する能動騒音制御手法は誤差マイクロホン近傍に静肃な領域を作り出すが， 低減効果のある範囲は周波数帯域が高くなるにつれて狭くなる ${ }^{(1)}$. この手法を人に用いる場合，広い周波数帯域 において効果を得ようとするならば耳近傍に誤差マイクロホンを配置する必要があり，このことは精神的な負担 となる可能性がある .この問題の解決策として, 仮想マイクロホン法 ${ }^{(2)}$ の中の一手法である Remote Microphone Technique (RMT) アルゴリズムが挙げられる ${ }^{(3)}$. この手法は, 事前に同定した一次音場に対する制御点 (仮想マ イクロホン) と制御点から離れた位置にあるマイクロホン (実マイクロホン) の間の伝達特性を用いて制御点の 信号を推定することで, 制御中には制御点にマイクロホンを配置することなく騷音低減を行うものである .

著者らはオフィス等で用いる簡易パーティションとRMT アルゴリズムを組み合わせたアクティブ遮音壁を作製 し, 弚の騒音低減効果について研究を行っている ${ }^{(4)}$.このアクティブ遮音壁を実環境に用いる場合に解決すべき 点の一つとして，騷音源が移動する状況で制御効果が劣化する問題がある．これは，騒音源の移動により一次音 場に対する実マイクロホンと仮想マイクロホン間の伝達特性が変化するため, 事前に同定した伝達特性との間に 差異が生じることが原因と考えられる．乥こで，本論文では複数の騒音入射方向に対する実マイクロホンと仮想 マイクロホン間の伝達特性を事前に同定して制御器内に保存しておき，制御中は複数のマイクロホン信号を用い て騒音の入射方向を推定し, 弚の入射方向に適した伝達特性に切り替えることて騒音源が移動する状況でも制御 効果を維持する手法を提案する．

\footnotetext{
* 原稿受付 2011 年 9 月 30 日

*1 正員，九州大学大学院工学府機械工学専攻（广819-0395＼cjkstart福岡県福岡市西区元岡 744 番地）

*2 (株) 安川電機（广806-0004 福岡県北九州市八幡西区黒崎城石 2 番 1 号）

*3 正員, 九州大学大学院工学研究院機械工学部門 (T819-0395 福岡県福岡市西区元岡 744 番地)

E-mail:koba@mech.kyushu-u.ac.jp
} 


\section{RMT アルゴリズムの原理および安定性}

RMT アルゴリズムのブロック線図を図 1 に示す . 図において $(n)$ は時間ステップである.$x(n)$ は騒音源の信号， $r(n)$ は参照信号, $d(n), e(n), y(n)$ は所望信号, 誤差信号, 制御信号を表す .また , $\boldsymbol{W}, \boldsymbol{G}, \boldsymbol{H}$ は一次経路特性, 二次経路特性，一次音場に対する実マイクロホンと仮想マイクロホン間の伝達特性である . 添字 ${ }_{v}, p, r e f$ は仮想 マイクロホン , 実マイクロホン , 参照マイクロホンに対応している . また , $は$ は推定值 , ‘は同定した值を示す .

適応フィルタ $C$ は Filtered-x LMS 法によって更新され，弚の更新式は以下で表される .

$$
\boldsymbol{C}(n+1)=\boldsymbol{C}(n)-\mu \hat{\boldsymbol{G}}_{v} \hat{\boldsymbol{e}}_{v}(n) \boldsymbol{r}(n)
$$

ここで, $\mu$ はフィルタ係数の更新幅を決定するステップサイズパラメータである.ブロック線図より，仮想マイク ロホン信号の推定值 $\hat{e}_{v}(n)$ は

$$
\hat{\boldsymbol{e}}_{v}(n)=\hat{\boldsymbol{d}}_{v}(n)+\hat{\boldsymbol{y}}_{v}(n)=\hat{\boldsymbol{H}}\left(\boldsymbol{e}_{p}(n)-\hat{\boldsymbol{G}}_{p} \boldsymbol{C}(n) \boldsymbol{r}(n)\right)+\hat{\boldsymbol{G}}_{v} \boldsymbol{C}(n) \boldsymbol{r}(n)
$$

となり，式 (2)を式 (1) に代入して整理すると以下のようになる .

$$
\boldsymbol{C}(n+1)=\left\{\boldsymbol{I}-\mu|\boldsymbol{r}|^{2} \hat{\boldsymbol{G}}_{v}\left(\hat{\boldsymbol{G}}_{v}-\hat{\boldsymbol{H}} \hat{\boldsymbol{G}}_{p}\right)\right\} \boldsymbol{C}(n)-\mu|\boldsymbol{r}|^{2} \hat{\boldsymbol{G}}_{v} \hat{\boldsymbol{H}} \boldsymbol{\alpha}
$$

ここで, $\boldsymbol{\alpha}=\boldsymbol{e}_{p}(n) / \boldsymbol{r}(n)$ である .この $\boldsymbol{\alpha}$ は $\boldsymbol{\alpha}=\boldsymbol{e}_{p}(n)\left(\boldsymbol{W}_{r e f} \boldsymbol{x}(n)\right)^{-1}=\left(\boldsymbol{W}_{p}+\boldsymbol{W}_{r e f} \boldsymbol{C} \boldsymbol{G}_{p}\right) \boldsymbol{W}_{r e f}^{-1}$ と表すことが できるので, 式 (3) に代入すると ,

$$
\boldsymbol{C}(n+1)=\left\{\boldsymbol{I}-\mu|\boldsymbol{r}|^{2} \hat{\boldsymbol{G}}_{v}\left(\hat{\boldsymbol{G}}_{v}+\hat{\boldsymbol{H}}\left(\boldsymbol{G}_{p}-\hat{\boldsymbol{G}}_{p}\right)\right)\right\} \boldsymbol{C}(n)-\mu|\boldsymbol{r}|^{2} \hat{\boldsymbol{G}}_{v} \hat{\boldsymbol{H}} \boldsymbol{W}_{p} \boldsymbol{W}_{r e f}^{-1}
$$

となる.$\left\{\boldsymbol{I}-\mu|\boldsymbol{r}|^{2} \hat{\boldsymbol{G}}_{v}\left(\hat{\boldsymbol{G}}_{v}+\hat{\boldsymbol{H}}\left(\boldsymbol{G}_{p}-\hat{\boldsymbol{G}}_{p}\right)\right)\right\}$ の最大固有値が1より小さい場合に $\boldsymbol{C}$ は以下の值に収束する.

$$
\boldsymbol{C}(\infty)=-\left\{\hat{\boldsymbol{G}}_{v}\left(\hat{\boldsymbol{G}}_{v}+\hat{\boldsymbol{H}}\left(\boldsymbol{G}_{p}-\hat{\boldsymbol{G}}_{p}\right)\right\}^{-1} \hat{\boldsymbol{G}}_{v} \hat{\boldsymbol{H}} \boldsymbol{W}_{p} \boldsymbol{W}_{r e f}^{-1}\right.
$$

したがって , 仮想マイクロホン信号 $e_{v}$ は以下の值に収束することがわかる .

$$
\boldsymbol{e}_{v}(\infty)=\boldsymbol{d}_{v}+\boldsymbol{G}_{v} \boldsymbol{C}(\infty) \boldsymbol{r}=\left\{\boldsymbol{I}-\boldsymbol{G}_{v}\left\{\hat{\boldsymbol{G}}_{v}\left(\hat{\boldsymbol{G}}_{v}+\hat{\boldsymbol{H}}\left(\boldsymbol{G}_{p}-\hat{\boldsymbol{G}}_{p}\right)\right\}^{-1} \hat{\boldsymbol{G}}_{v} \hat{\boldsymbol{H}} \boldsymbol{H}^{-1}\right\} \boldsymbol{d}_{v}\right.
$$

この式 (6) は伝達特性 $\boldsymbol{G}_{p}, \boldsymbol{G}_{v}, \boldsymbol{H}$ の同定精度が制御効果に与える影響を表している. 仮に $\hat{\boldsymbol{G}}_{p}=\boldsymbol{G}_{p}, \hat{\boldsymbol{G}}_{v}=\boldsymbol{G}_{v}$ ， すなわち二次経路特性が完全に同定できたとしても， $\boldsymbol{e}_{v}(\boldsymbol{\infty})=\left(\boldsymbol{I}-\hat{\boldsymbol{H}} \boldsymbol{H}^{-1}\right) d_{v}$ となるため，騒音源位置が变化 したときに生じる，事前同定した $\hat{\boldsymbol{H}}$ と実際の伝達特性 $\boldsymbol{H}$ の間の差異が制御効果に悪影響を与えることがわかる この問題に対し，本論文では複数の騒音入射方向に対応した $\hat{\boldsymbol{H}}$ を事前に同定して制御器内に保存しておき，制御 中に騒音入射方向に適した $\hat{\boldsymbol{H}}$ に切り替えるシステムを提案する.

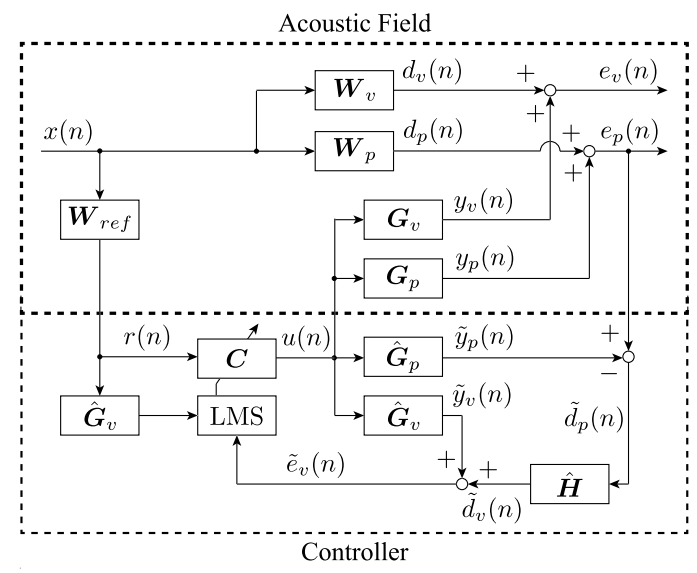

Fig. 1 Block diagram of the RMT algorithm 


\section{3. 騒音入射方向の推定法}

騒音入射方向推定には多くの研究が行われているが ${ }^{(5)}$, 計算負荷低減のために相互相関関数を用いた手法を採 用する.騒音源が床面から $1.0 \mathrm{~m}$ の水平面内で移動することを想定し，2 本のマイクロホン信号を用いて騒音入射 方向を推定する . 図 2 に示すような角度 $\theta$ の方向から入射する音を 2 つのマイクロホンで取得した場合，平面波 と仮定すると, $\theta$ はマイクロホン間の音の到達時間差 $T_{d}$, マイクロホン間の距離 $d$ および音速 $c$ を用いて以下で 表すことができる

$$
\theta=\sin ^{-1}\left(\frac{c T_{d}}{d}\right)
$$

この到達時間差 $T_{d}$ の算出に相互相関関数を用いる .2 つのマイクロホン信号 $x_{1}(t), x_{2}(t)$ の離散データ $x_{1}(i)$, $x_{2}(i)(i=0,1, \cdots, N-1)$ を用いて相互相関関数 $R x_{1} x_{2}(j)(j=0,1, \cdots, M-1)$ を次式で求める.

$$
R x_{1} x_{2}(j)=\frac{1}{N} \sum_{i=0}^{N-1} x_{1}(i) x_{2}(i+j)
$$

$j=k$ のときに相互相関関数が最大值をとった場合，サンプリング周波数を $f_{s}$ とすると $T_{d}=k / f_{s}$ となり，入射 方向の推定值 $\hat{\theta}$ は次式で求められる.

$$
\hat{\theta}=\sin ^{-1}\left(\frac{c k}{d f_{s}}\right)
$$

以上の手法を用いて，無響室での実験により騒音入射方向の推定精度について確認する $.1 .2 \mathrm{~m} \times 1.2 \mathrm{~m}$ の大き さのパーティション上部に $0.6 \mathrm{~m}$ の間隔でマイクロホンを 2 つ配置し, 2 つのマイクロホンの中点を中心とする半 径 $1.5 \mathrm{~m}$ の同心円上に騒音源を配置する (図 3 ). 騒音源位置 $\theta$ を $0^{\circ}$ から $25^{\circ}$ まで $5^{\circ}$ 刻みで動かし, 各位置におい て 2 つのマイクロホン信号を用いて相互相関関数を求め, 音の入射方向の推定值 $\hat{\theta}$ 算出する .このときのサン プリング周波数は $100 \mathrm{kHz}$ とし，1 回の入射方向推定にかかる時間は $1.77 \mathrm{~ms}$ である . 推定值の評価は各騒音源位 置における推定値の 20 回平均によって行う.

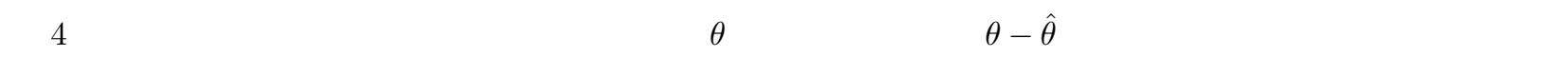
て $1^{\circ}$ 以内の精度で推定できていることが確認された .

\section{4. 騒音源が移動する状況での提案法による制御実験}

提案法による制御効果について無響室での実験により確認する.実験は図 5 に示すような構成で行う．制御用

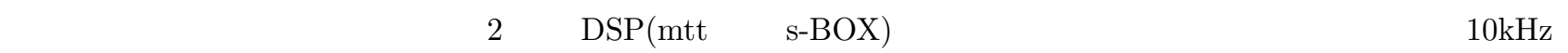
$100 \mathrm{kHz}$ とする.制御対象音は $4 \mathrm{kHz}$ で帯域制限した白色雑音，適応フィルタ長は 256 とする.制御前に以下に示 す手順を行う .

1. 仮想マイクロホン位置にマイクロホンを配置し，制御音源から白色雑音を出力し $\boldsymbol{G}_{p}$ および $\boldsymbol{G}_{v}$ を同定する. 同定には LMS 法を用い，誤差信号が十分収束した後 FIR フィルタの形で制御器用 DSP 内に保存する .

2. 騒音源を $\theta=0^{\circ}$ から $25^{\circ}$ まで $5^{\circ}$ 刻みで移動させ, 各位置で白色雑音を出力し, 弚の位置における $\boldsymbol{H}$ を同定 する . 同定には LMS 法を用い, 誤差信号が十分収束した後 FIR フィルタの形で制御器用 DSP 内に保存する

3. 仮想マイクロホン位置に配したマイクロホンを取り除く .

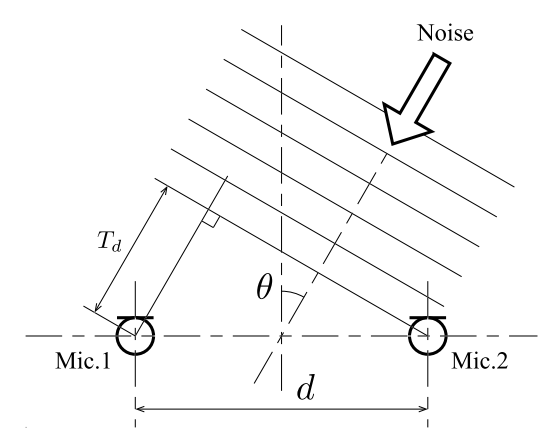

Fig. 2 the Method of estimate noise Incident direction 
制御中は騒音入射方向検出用 DSP で推定した入射方向 $\hat{\theta}$ は角度に比例した電圧として出力され，制御用 DSP に より取り込まれて再び角度情報に計算される. 求めた角度情報より制御器内に保存してある事前同定した $\hat{\boldsymbol{H} の う ~}$ ち最も近い角度のものを適切な $\hat{\boldsymbol{H}}$ として採用する . 以上の手法を用いて，移動する騒音源に対して制御を行い， 弚の効果を調べる.騒音源はパーティション上部に $0.6 \mathrm{~m}$ の間隔て配置したマイクロホンの中点を中心とする半径 $1.5 \mathrm{~m}$ の同心円上を人の手によって移動させる .

\section{$4 \cdot 1$ 騒音源を断続的に移動した場合の制御効果}

騒音源を $\theta=0^{\circ}$ の位置に配置し，約 5 秒間静止した後約 5 秒かけて $5^{\circ}$ 移動させる動作を $\theta=0^{\circ}$ から $25^{\circ}$ まで 繰り返し，光のときの制御効果を測定した . 图 6(a) は騒音入射方向の変化，図 6(b) は光のときの仮想マイクロホ ン位置の信号を示す．図 6(a) 縦軸は騷音入射方向，図 6(b) 縦軸は信号の振幅を表し，横軸は共に時間である.騒 音源の移動開始，停止時刻を破線で示している . 図より，移動中に制御効果が劣化するものの，移動終了後にはす ぐに制御効果を得られることが分かる。

\section{$4 \cdot 2$ 騒音源を連続的に移動した場合の制御効果}

次に騒音源を $\theta=0^{\circ}$ の位置に配置し，約 5 秒間静止した後約 20 秒かけて $25^{\circ}$ まで連続的に移動させたときの 制御効果を測定した．弚の結果を图 $7(\mathrm{a})$ ，(b) に示す. 各図の軸は図 6 と同樣である. 図より, $\theta=25^{\circ}$ で停止し た後はすぐに制御効果を得られることが分かる．また，移動中も制御効果が悪化するが，全く制御効果が無くな ることはない .

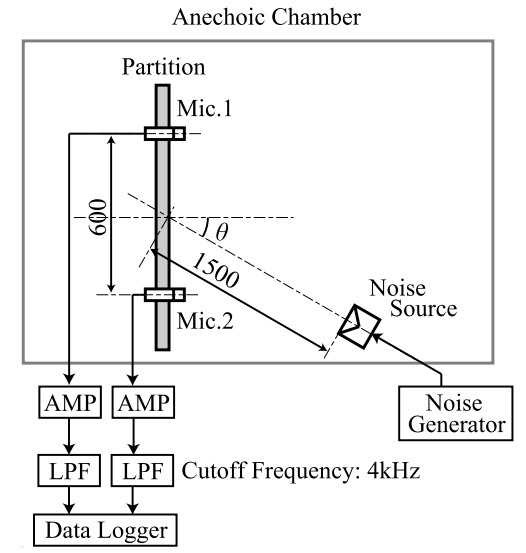

Fig. 3 Experimental setup for estimate noise incident direction

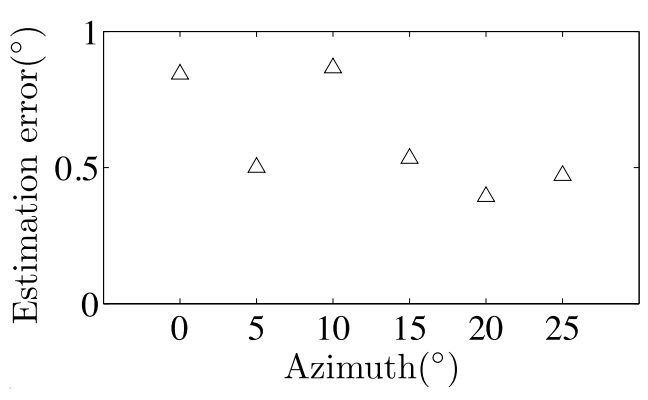

Fig. 4 Error of estimate incident direction

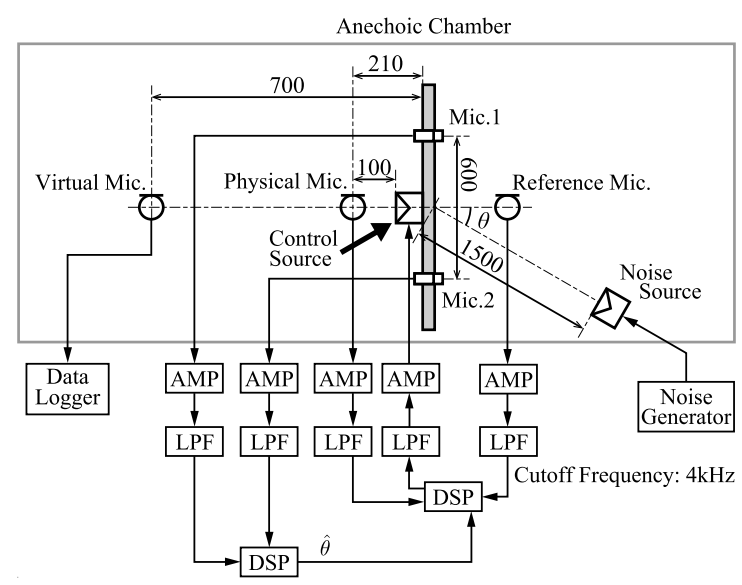

Fig. 5 Experimental setup for control in change of noise incident direction 


\section{5. まと め}

騒音源位置が変化する環境での RMT アルゴリズムの制御性能の向上を目指し，あらかじめ複数の騒音入射方 向に対応した仮想誤差推定フィルタを同定して制御器内に保存しておき, 制御中に変化する騒音入射方向に適し たものに切り替えるシステムを提案した . 制御中の騒音入射方向の検出には 2 つのマイクロホン信号の相互相関 関数を用いた方法を採用し，無響室による実験の結果，誤差 $1^{\circ}$ 以内の精度で推定できることを確認した . 提案す るシステムを用いて，断続的および連続的に移動する騒音源に対して無響室において制御実験を行った結果，移 動中は制御効果が劣化するものの，事前同定を行った騒音入射方向近傍に騒音源がある場合は良好な制御効果が 得られた . 移動中の制御効果は, 騒音入射方向に対応した仮想誤差推定フィルタの同定をより細かい刻み幅で行 うことで向上させることができると考えられる．

謝 辞

本研究は科研費 (22760174) の助成を受けたものである.

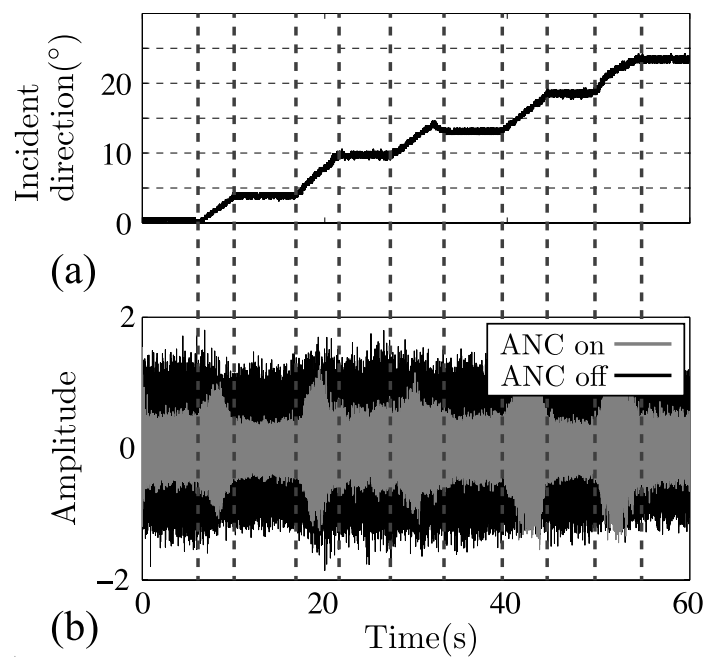

Fig. 6 (a) The trajectory of noise incident direction (b) Control effect in intermittent moving of noise source

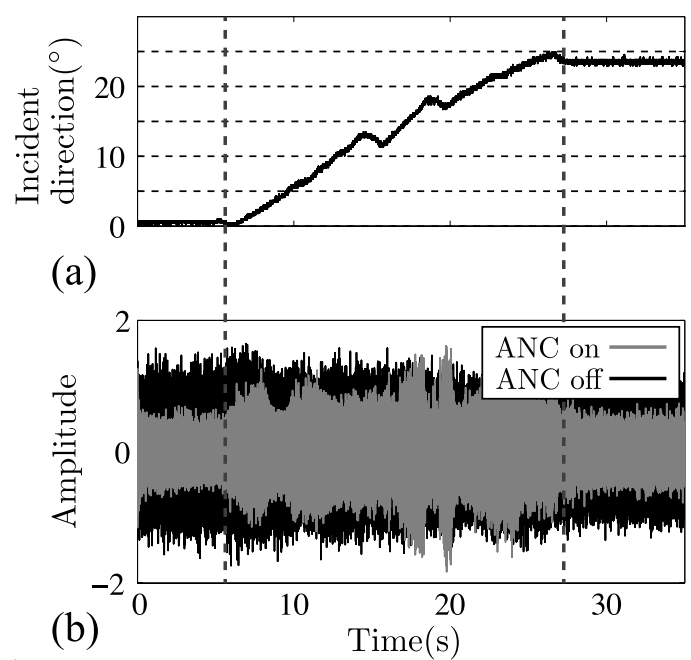

Fig. 7 (a) The trajectory of noise incident direction (b) Control effect in continuous moving of noise source

\section{文献}

(1) Elliott, S.J., Joseph, P., Bullmore, A.J., and Nelson, P.A., "Active cancellation at a point in a pure tone diffuse sound field", Journal of Sound and Vibration, Vol. 120, No. 1(1988), pp. 183-189.

(2) Moreau, D., Cazzolato, B., Zander, A., and Petersen, C., "A Review of Virtual Sensing Algorithms for Active Noise Control", Algorithms, Vol. 1(2008), pp. 69-99.

(3) Roure, A., Albarrazin, A., "The remote microphone technique for active noise control", In Proceedings of Active 99(1999), pp. 1233-1244.

(4) 近藤大介, 雉本信哉, 松田浩一, 木庭洋介, “一般居室用アクティブ遮音壁による騒音制御”, In Proceedings of the Dynamics and Design Conference 2010 (CD-ROM) (2010), No.706.

(5) 例えば, Liu, C., Wheeler, B.C., O’Brien, W.D., Jr., Bilger, R.C. Lansing, C.R., and Feng, A.S., "Localization of multiple sound sources with two microphones", Journal of the Acoustical Society of America, Vol.108, No. 4(2000), pp. 1888-1905. 